\title{
Integrated Development of Rural Energy Systems through Pocket Area Approach for Energy Services: The REDP Experience, Nepal
}

\section{Thakur Raj Devkota}

\begin{abstract}
Micro-hydro technologies together with other renewable energy technologies are being disseminated in various parts of Nepal to provide basic energy services as per the demand of the individual household or a particular community. These technologies use an integrated approach that helps address rural energy needs by providing basic rural energy services. The planning and implementation of rural energy systems in an integrated manner through the 'Pocket Area Approach', which takes into account the entire geographical area for the intervention, has been experimented in some of the pockets area in the country and is found quite effective to cater to basic rural energy services to the entire population of the area. This paper illustrates the approach and results achieved by Rural Energy Development Program (REDP).
\end{abstract}

Key words: Micro-hydro, Participatory Rural Energy System, Pocket Area Approach, Nepal

\section{The Context}

Provision of modern forms of energy services has become imperative to raise the living conditions of the rural poor. As the vast majority of Nepal's population lives in the rural areas (about 85\%), the challenge is to extend the central energy systems (national electricity grid). Due to remote and scattered settlement patterns, lack of sufficient power in the central grid systems, and low levels of economic activities in the rural areas, it is considered a prudent and practical approach to provide energy services to the people of these far-flung localities through the development of decentralized energy technologies based on renewable sources to meet the rural energy needs. It is estimated that about $56 \%$ of the country's population has access to electricity. Their share contribution from the decentralized electricity system of micro-hydro (less than $100 \mathrm{~kW}$ ) and solar home systems is estimated to be around seven percent.

Most settlements of the hill and mountainous regions of the country are endowed with the vast natural resources (mainly water, land, forest, etc.) that provide ample opportunities for the promotion of Renewable Energy Technologies (RETs) to address the basic energy needs.

The Rural Energy Development Program (REDP) is a joint initiative of Government of Nepal (GoN) and United Nations Development Program (UNDP). REDP aims to enhance rural livelihoods through the promotion of rural energy systems, specifically micro-hydro, for sustainable development and poverty alleviation. It is ongoing in 40 hill districts of the country to promote rural energy systems for better rural livelihood and environment preservation following an holistic approach to development. The uniqueness of the program lies in its launching of community mobilization works. In almost 15 years of operation, REDP has been successful to help generate around $5500 \mathrm{~kW}$ of micro-hydro electricity benefitting some 50,000 rural households. Three hundred micro-hydro projects have been completed to date and another $\mathbf{2 0 0}$ are under construction. REDP has been rec- ognized nationally and internationally for its impressive decentralized implementation modality putting local people at the helm. It has won the Energy Globe Award2000, Global-100 Eco Tech Award-2000, and Pearl of Knowledge Award-2005, to name a few.

\section{The Rural Energy Needs}

In order to enhance the rural livelihoods and preserve the local environment, it has been widely accepted that access to modern energy services by the community people is imperative. This applies to the reduction in the use of solid fuels (i.e., biomass fuels) in fulfilling energy requirements. Energy analysts further argue that community people should be raised up the energy ladder at least by one step such that if the poverty reduction efforts are seriously considered they will have electricity for household lighting and a liquid or gaseous form of energy for other thermal energy needs (UNDP 2000). But, paradoxically, about $86 \%$ of the total energy consumption is from biomass resources (about $76 \%$ fuelwood and nearly $10 \%$ animal waste).

In rural Nepal, there are basically two types of rural energy needs. One is for a modern source of energy for lighting, running household appliances and operating small business enterprises, and the other is for meeting the thermal energy needs, especially for cooking and space heating. Experience and best practices have shown that the right solution for the first of these needs is the harnessing of locally available water resources through the installation of micro-hydropower plants to provide electricity in a decentralized way to meet the household lighting needs as well as running appliances like TV, computer, radios, etc., and operating small scale mills and enterprises. Where the installation of micro/mini hydro systems including pico hydro (less than $1 \mathrm{~kW}$ ) does not seem viable, solar electricity systems could be the right solution. In most cases, however, the electricity from the micro-hydropower as well as Solar PV is not sufficient to meet other basic energy needs, especially for cooking/heating. For this, a wise option is the promotion 
of biogas plants, improved cook stoves, or metallic/air induced stoves. Thus, an integrated approach to promote different energy technologies to cater the needs of the people seems to be the practical approach. It has been in practice in some programs, including the Rural Energy Development Program (REDP).

\section{Participatory Rural Energy Planning and Implementation}

It has been proven that participatory planning and implementation of rural energy technologies is the best way to encourage sustainable development, operation and management of technologies. The process involves the active participation of the concerned community people in all stages of the development process; viz., planning, implementation, operation, and management. The process gives due attention towards empowering local stakeholders to identify their energy needs, assess the natural resources and energy potentials, as well as making appropriate decisions in selecting the right technologies. In Nepal, Village and District Development Committees (VDCs and DDCs) are the main stakeholders that support and facilitate the planning process including the mobilization of local resources. Subsidies and investments for development are channeled through them as per the government's rules and regulations.

The social mobilization process is one of the best ways to empower local beneficiaries and get them organized and mainstreamed in the development process. The process helps to build social capital at the local level, the key to the successes of all local initiatives. It also helps to harness the potential of local people to help themselves. Formation of local level broad-based grass-roots institutions is considered very important under the social mobilization process, and it is always desirable that these institutions become engaged in various socio-economic activities and not confined to rural energy related activities alone.

The REDP social (community) mobilization process revolves around six thematic areas that supports the holistic approach to development, namely: organization development, capital formation, skill enhancement, technology promotion, environment management and empowerment of the vulnerable communities (REDP 1997).

\section{The Pocket Area Approach Concept Practiced by REDP}

This approach has been successfully implemented in some of the pocket (cluster) areas and is under implementation in others. Normally, access to modern energy services in rural areas is not assured for all households of an entire geographical area owing to scattered settlement pattern, incapacity of potential users to afford services, technical constraints, etc. Furthermore, some technological options might not be sufficient to provide the basic energy services required. Given this, the integrated development of rural energy systems through pocket area approach is both effective and instrumental in providing basic energy services to the entire mass of a certain pre-identified area, desirably the whole geographic area where people have shared common values, cultures and resources since time immemorial.

Under the integrated participatory approach, an entire (whole) geographic area comprised of several settlements, villages, wards or VDCs is considered for program intervention, irrespective of political boundaries, to promote rural energy systems development. This approach attempts to promote basic energy services to all households of the area considered by means of decentralized rural energy systems based on renewable resources, micro-hydro being the principal technology. Normally, several micro-hydro systems are identified to be installed with the aim of providing access to rural electricity to all the households in a 'pocket' area. If some households seem to be left out due to various reasons, promotion of solar home systems providing access to decentralized electricity by all households of the area remains the principal objective.

Based on demand, potentials and affordability, as well as acceptance of the technology, other rural energy technologies such as biogas plants (preferably with toilet connection), improved cook stoves, and metallic/air induced stoves are promoted to meet energy needs for cooking and heating. To effectively attain the goal in a sustainable way, the special social mobilization package is implemented prior to technological intervention in order to organize, sensitize, and make the community people aware of the soon-to-start technological intervention. Planning for the promotion of targeted technologies is done through the participatory bottom-up rural energy planning process with members of the local bodies as the real facilitators/supporters.

\section{The Pockets and the Advantages}

All the households of the pocket areas are provided basic rural energy services through decentralized energy systems. Based on local geographical configuration, the various pockets are: Urja Arc (Energy Arc), Urja Upatyaka (Energy Valley), Urja Strip (Energy Strip), Urja Gaon (Energy Village), and Urja Corridor (Energy Corridor). Successful implementation of the approach has demonstrated that if planned deliberately and specifically to meet rural energy needs, even the rural energy technologies that are based on locally available natural resources and are mostly indigenous could be instrumental in addressing the basic rural energy needs in a sustainable way with community's full ownership and management. As all households of the identified area are assured access to energy services, the approach supports social justice, inclusiveness and mainstreaming of all in local development process. 


\section{Success Story on the Formation of Urja Upatyaka (Energy Valley)}

The REDP launched its program activities in Sarkuwa and Paiyun Village Development Committees (VDCs) in Baglung District, Nepal, in September 1997 and in Rangkhani VDC in July 1999 with the objective of developing the whole river basin and the whole valley through the capacity building of the local communities to plan, implement and manage the rural energy systems, especially micro-hydro schemes and micro-watershed management within the framework of the community mobilization process. REDP also installed several micro-hydro schemes in the initial years in these VDCs, such as improved cook system (ICS), solar home system (SHS), toilet attached biogas plants, pico/peltrics, etc. REDP also formed 149 community organizations (COs) in these three VDCs for carrying out specific activities. And functional groups (FGs) and income generating (IG) and committees have also been formed and are operational.

The main thrust of the program is the development of micro-hydro demonstration schemes (MHDSs) together with other renewable energy technologies, to provide various opportunities to the people for enhancing their livelihoods. Accordingly, several MHDSs were implemented by community members through the support and facilitation of REDP. Planning and implementation of the 24kW Theule Khola MHDS has benefitted 290 households in Sarkuwa VDC, and the 22kW Kalun Khola MHDS has benefitted 230 households in Paiyun VDC. Seventeen micro-hydro schemes, each with capacity ranging from 8 to $26 \mathrm{~kW}$ were planned and commissioned in later years. The District Development Committee/District Energy and Environment Section (DDC/DEES) of Baglung District also provided technical as well as capacity building support for capacity enhancement of the Nanda micro-hydro (MH) plant in Damek, from 3 to $10 \mathrm{~kW}$. A total of $166 \mathrm{~kW}$ of electric power is being generated by these $17 \mathrm{MH}$ systems (including nine pico/peltrics) to benefit 1,745 households in the Upatyaka (valley). This is the largest number of $\mathrm{MH}$ systems developed through the utilization of flow from a single river system in Nepal, on the Urja Khola (Energy Stream) and its tributaries.

The 46 solar home systems installed mainly in Sarkuwa and Rankghani VDCs are providing electricity to the far-flung settlements not served by those $17 \mathrm{MH}$ systems. To meet other rural energy needs, mainly for cooking, almost all households have installed either toilet-connected bio-gas plants or improved cooking systems.

The vision of the program to have "access to rural electricity" by all community members has materialized in the entire Upatyaka (valley), thanks to the REDP's visionary Pocket Area Approach. If one passes through the valley at night, he or she will not only be astonished but thrilled to see the entire river basin (valley) and surrounding hills completely illuminated by the rural electricity generated by the community people themselves, from the support provided by the program. The share contribution of REDP for this targeted achievement is above $50 \%$. By comparison, normally the cost share by DDC, VDC, and villagers is only about $5 \%, 5-10 \%$, and $15 \%$, respectively. Villagers normally provide their $15 \%$ share mostly in volunteer labor plus some cash. Furthermore, villagers need to take $15-20 \%$ cash credit as a bank loan for sharing the cost.

With the advent of rural electricity, the lifestyle of community people has changed significantly. It is interesting to note that while there are 14 hours of load shedding in all areas served by the national utility, there is no load shedding in pocket areas where these micro-hydro schemes are located.

With so many (total 17) micro-hydro schemes, including pico/peltrics installed, the majority of the people of these VDCs have started to refer the Theule or Kalun Khola as the Urja Khola (Energy Stream) and the entire river basin supported by the Urja Khola is known as Urja Upatyaka (Energy Valley).

It has been observed that successful implementation of this approach in some pocket areas has helped create social harmony, integration, cooperation, and bondage amongst the residents, thereby lessening social conflict, mistrust and individualistic attitudes. It further encourages and stimulates community people to move forward in fulfilling common goals, especially through the mobilization of common property resources (CPRs). The approach has effectively instilled a sense of ownership, confidence and pride amongst community people so that they are able to harness their own potentials to help themselves. Thus, the integrated approach of promoting different renewable energy technologies to meet the basic rural energy needs seems quite effective (REDP 2000).
This approach has distinct advantages over the conventional approach of dissemination of technologies on a sporadic basis. The approach strives to deliver services following the integrated energy planning process for a given area to meet the basic local rural energy needs in their totality. This not only assures the provision of basic energy services to all the people but also leads to program efficiency in terms of service delivery and cost effectiveness. The mix of several energy technologies that provide energy services differently results in impacting the lives of the local people and environment very broadly. Assured and equitable access to modern forms of energy services by all people of the whole area lowers the risk of social tension that could otherwise emerge in the society 
(as has been noticed in so many other communities). The central and the local governments do not have to allocate huge resources to extend central energy systems under the integrated pocket area approach due to none or partial delivery of energy services. As the promoted energy technologies are decentralized and based on renewable resources, the actions help to contribute considerably to greenhouse gas reductions and lessen adverse climate change effects. As micro-hydro systems remain the principal technologies under this approach, the installation of several systems within the pocket creates opportunities for the development of mini-grid systems in the area and their eventual connection to the national grid.

\section{Conclusion}

The integrated and participatory development approach is good for development agencies that work for the promotion of renewable energy technologies, especially to internalize the concepts and feasibly replicate the model. The agencies and development partners that work only with certain technologies like biogas, improved cook system (ICS), micro-hydro, etc., can achieve better coordination and linkage to assure access to basic energy services by complementing their activities. With guidance, support and coordination from government agencies, development partners could work on providing basic energy services in the remaining pockets that lie scattered in the nooks and corners of the country.

Thakur Raj Devkota, has an MSc degree in Industrial and Civil Engineering, and a Bachelor's degree in Public Administration. He has more than 14 years experience in rural energy systems, particularly micro-hydro technology. He has been working in REDP of AEPC (Alternative Energy Promotion Center) since 1997 in various capacities. He also worked as a civil engineer for the Agricultural Development Bank, Nepal, mainly in rural energy systems. He has published various papers under REDP and in national dailies, magazines and various journals. Presently, he is Senior Rural Energy Development Advisor in AEPC/REDP.

Corresponding address: thakurrajdevkota@yahoo.com.

\section{References}

REDP (Rural Energy Development Program), 1997, Community Mobilization Guidelines, Kathmandu: REDP.

REDP (Rural Energy Development Program), 19972010, Progress Report of Energy \& Environment Section, Baglung, Kathmandu: District Development Committee.

REDP (Rural Energy Development Program), 2000, District Energy Planning and Implementation Guidelines, Kathmandu: REDP.

REDP (Rural Energy Development Program), 2000, Urja Upatyaka (Energy Valley), v.16, Kathmandu: REDP.
REDP (Rural Energy Development Program), 2002, Technical Guidelines for Installation of Micro-hydro Schemes, Kathmandu: REDP.

REDP (Rural Energy Development Program), 2010, Micro-hydro Implementation Guidelines, Kathmandu: REDP.

UNDP (United Nations Development Program), 2000, World Energy Assessment and Challenge of Sustainability, Kathmandu: UNDP.

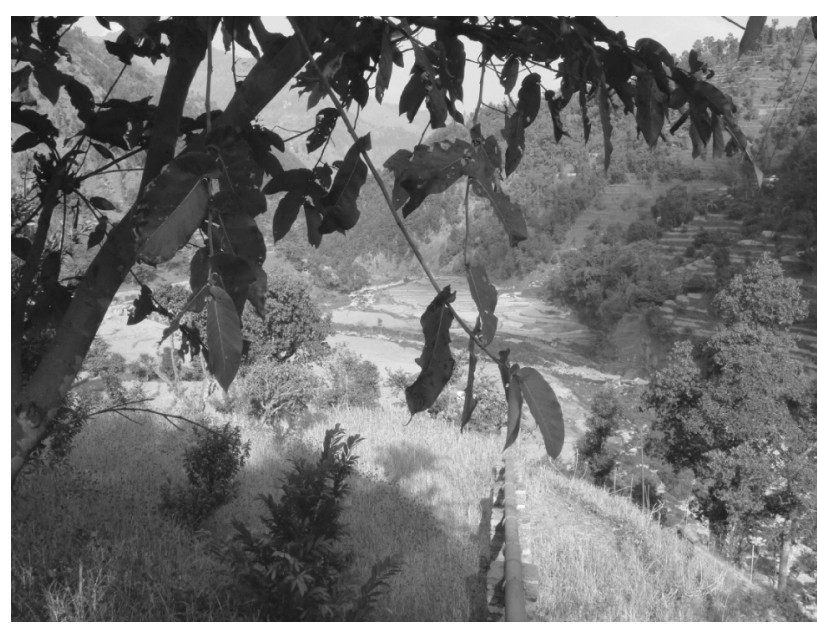

Energy Valley in Baglung District, Nepal

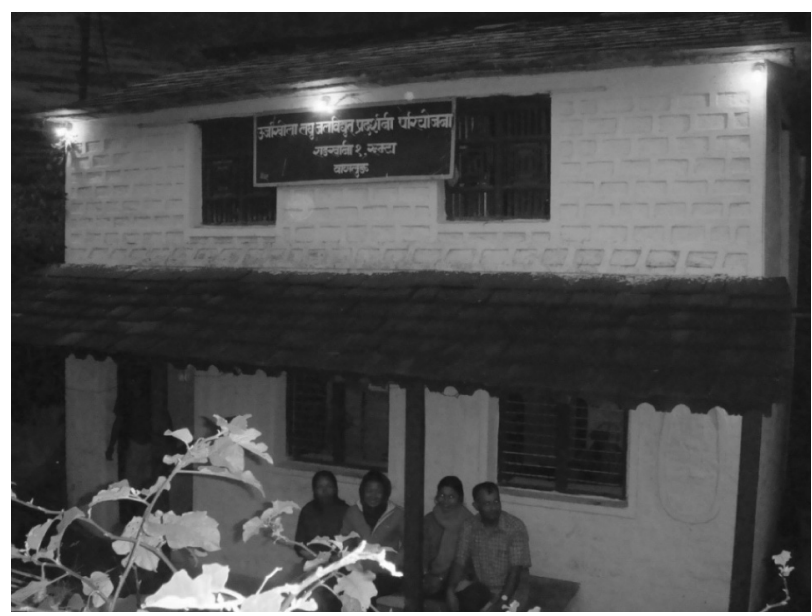

Urja Khola Micro-hydro Demonstration Project

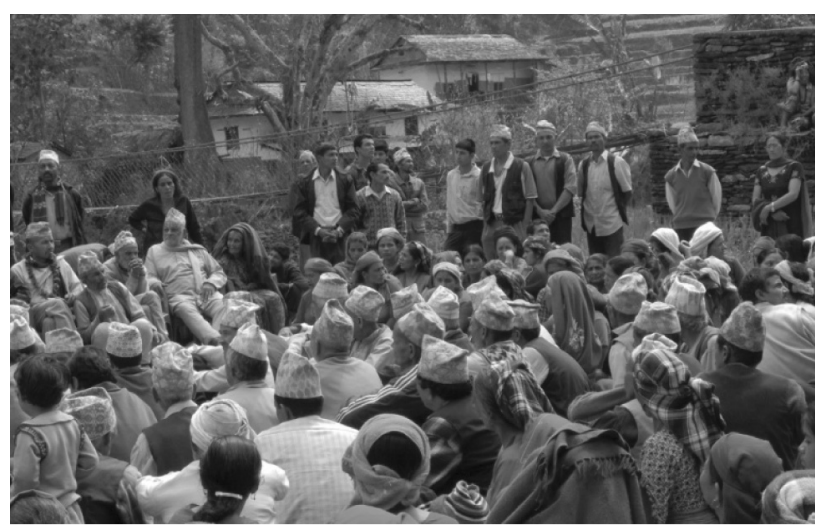

Micro-hydro Users in a Meeting 